\title{
The transformation of scientific journal publishing: Open access after the Berlin 12 Conference
}

\author{
Ralf Schimmer \\ Max Planck Digital Library, Munich, Germany \\ E-mail: Schimmer@mpdl.mpg.de
}

\begin{abstract}
In the last 10-15 years, Open Access has become a shared vision of many if not most of the world's national and international research councils. Open Access as a principle is very well established in the international discourse on research policies; however, Open Access as a practice has yet to transform the traditional subscription-based publishing system, which is as vigorous and prosperous as ever, despite its inherent restrictions on access and usage and its remarkable detachment from the potentials of a 21 st century web-based publishing system. OA2020 is a transformative initiative trying to bring a new approach to the transactional side of the publishing system and the ways in which its cash flow is organized. Publishing and financial data are brought together in a way to demonstrate that such a switch would indeed be feasible. OA2020 lays out the path for how this transformation could happen so that Open Access to research results would finally be a reality from the moment of their publication.
\end{abstract}

Keywords: Open access, gold road, business model, transformation, scientific publishing, data analysis

Since 2003, the Berlin Conferences have been nodes in a journey whose rationale is to achieve Open Access (OA) in journal publishing by transforming outdated commercial practices into a postsubscription business model. Until very recently, the principal focus of this initiative has been on generating awareness, creating mandates and devising various practical measures, all predicated on an effort to move the researcher towards $O A$. At this point, only about $15 \%$ of scholarly articles per year are available through OA. This proportion, which currently increases by about one percentage point each year, does not of itself exert any transformative pressure on the subscription system. It therefore seems to be time to change gear and address the challenge from the opposite direction, moving OA towards the researcher.

\section{Rebooting the approach to $\mathrm{OA}$}

Our revised aim is to create the conditions in which OA supports researchers in every aspect of their practices, from accessing existing outputs to publishing the results of their own research. From this perspective we can see that it is not the researchers who should be obliged to change; rather, it is the publishing system and its underlying business model that needs an overhaul. For intellectual and career reasons, researchers will naturally aim to publish in established, prestigious journals, so - along with the whole business of scholarly publishing - these must be the focus of our persuasive efforts so that the OA project can inspire an industry-wide shift in the approach to journal-publishing. 
Until recently, the entrenched practices in academic publishing have led all sides in the industry to view the current business model as inevitable. The traditional subscription system involves a cash flow philosophy that is predicated on inherent restrictions on use/reuse rights. The task ahead is to induce an inversion of this, such that the cash flow is legitimised by an offer of publication services that deliver a truly OA environment. By shaking off old habits of mind we can deconstruct the functions of publishing to show that registration, certification, dissemination and (possibly) archival record are at the core. We believe that the underlying business model can be detached from these essential processes and be reengineered in a way that gives scholarship a proper platform for the digital 21 st century.

Articulating this goal inevitably provokes discomforts and challenges, since these proposals are counterintuitive to the knowledge and experience of many (or even most) of those in positions of authority: library directors, heads of acquisitions departments, senior academics in institutions of learning. Typically these leaders have been hampered in their strategic analyses by the insufficient gathering of data or other evidence within their institutions and by understandable anxieties about the financial implications of a transition to OA. The transformation must of course be based on a demonstration of its financial viability; there will need to be pilot programmes and the elaboration of the necessary workflows; and a large international coalition will need to coalesce to commit to the transformation to OA and develop a transition plan.

\section{Bringing data and analysis to the $\mathrm{OA}$ debate}

To allay fears about an insufficiency of resources or that an OA world would be even more expensive than the current subscriptions system, the Max Planck Digital Library (MPDL) published a white paper in the spring of 2015 that has become a reference document for the OA movement [1,2]. We drew on data from ten years-worth of publishing from all over the world, paying particular attention to the issue of corresponding author share, which is crucial to the viability of an article-processing charge (APC) scheme. Our claim, based on current global annual operating figures, is that there is sufficient 'money' in the system to finance the outputs of scholarly communication in an OA world without financial risk. Indeed, not only will additional resources be unnecessary, but the savings that arise will enable the correction of funding imbalances, and the emergence of new and creative approaches to informationsharing.

The starting-point of our analysis is the figure of $€ 7.6$ billion as the total global budget. ${ }^{1}$ The subscriptions-based market produces 1.5 million scholarly articles on the World of Science (WoS) index, or up to 2 million overall; this implies a cost-per-article of approximately $€ 5,000$ for WoS articles, or $€ 3,800$ overall. By contrast we note that, in an observably consistent picture, the existing APCs are substantially less than $€ 2,000 .{ }^{2}$ If 2 million research papers are published at an APC of $€ 2,000$, then the resultant total of $€ 4$ billion gives a $45 \%$ buffer within the current system, allowing significant investment in new and improved services, remaining subscriptions, as well as other adjustments. This overview is summarized in Fig. 1.

\footnotetext{
${ }^{1}$ This figure is widely accepted in the publishing industry. It is reported by various finance analysts such as SIMBA, and appears in the annual reports of the STM publisher association, cf. http://www.stm-assoc.org/2015_02_20_STM_Report_2015. pdf.

${ }^{2}$ The most comprehensive source of APC evidence, the German-based Open APC Initiative, currently reports a median fee of just below $€ 1,300$; cf. https://github.com/OpenAPC/openapc-de; a visualization layer for the same data can be found at: http://treemaps.intact-project.org/.
} 
The global scholarly journal market and its financial dimensions

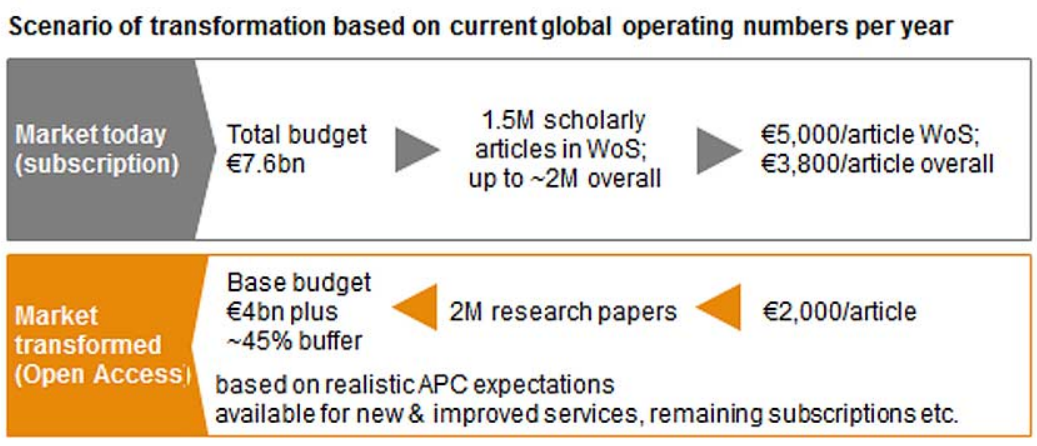

An $O A$ transformation seems to be possible without financial risks

Fig. 1. The financial dimensions of the global scholarly journal publishing.

In the past, various parties have presented cost projections that are based on naïve or inaccurate analyses. An important dimension of our work is the recognition of the need to de-duplicate the raw data that is drawn from bibliographies and institutional repositories so as to reflect the reality that research is increasingly co-authored: by co-authors from different institutions and sometimes beyond national borders. While authors may be recorded recurringly in the bibliographies of all the home institutions, the costs of publishing services are a one-time event. In terms of the share of corresponding author papers, there are differences around the world. In Europe, the proportion is approximately $70 \%$; in the larger and more insular contexts of China and the US, the share is higher, while in smaller or less research-intensive countries the share is lower.

Our analysis of the publications volumes in Germany and Great Britain - which are remarkably close to each other - show that whether one relies on a conservative view of publishing costs (i.e., assuming $€ 2,000$ per publication) or an actual average APC (i.e., taking the $€ 1,300$ from the Open APC Initiative), these countries' spending budgets are currently substantially greater than the costs of an OA model (Figs 2 and 3). Experts assess the spending of the German higher education institutions for their journal subscriptions to be in the range of $€ 200$ million per year. For the UK, those estimates vary from $£ 160$ million per year (according to Jisc Collections) to $£ 192$ million (according to Research Libraries UK).

We conclude that even for research-intensive countries with high publication volumes an orderly transition to OA publication charges is without financial risk, and will free up resources for additional investment in new services.

\section{Showing solidarity and support for the transition to $\mathrm{OA}$}

There are many parallel initiatives around Europe that support OA in various forms, but these are not yet connected to a shared goal. This fragmented impetus shows that this is a timely moment to develop an international transformation programme to align and capitalise on the diverse efforts being made to create an open access environment. 


\section{Germany}

Publication volumes and corresponding author shares Articles and reviews in Web of Science

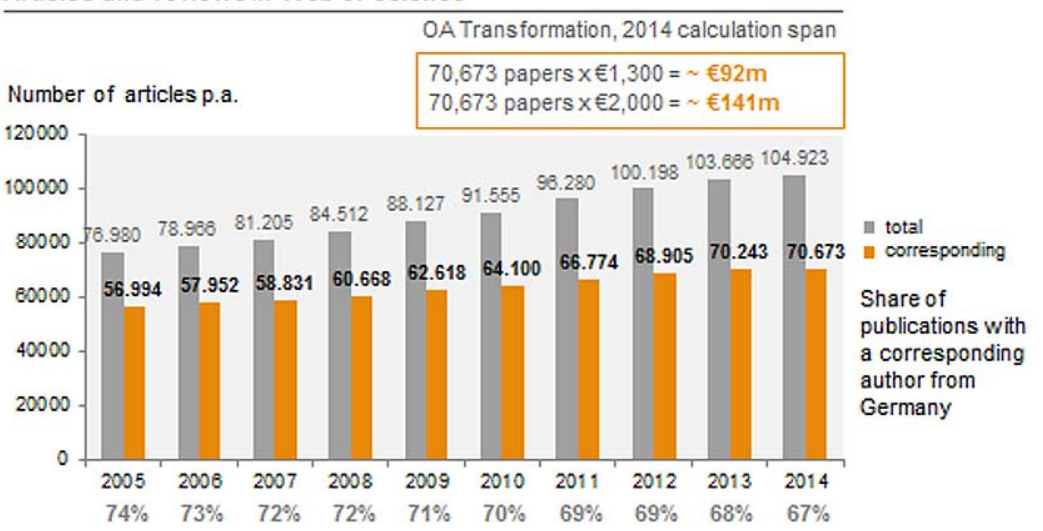

Fig. 2. Cost projections for a full-fledged OA scenario in Germany.

\section{Great Britain}

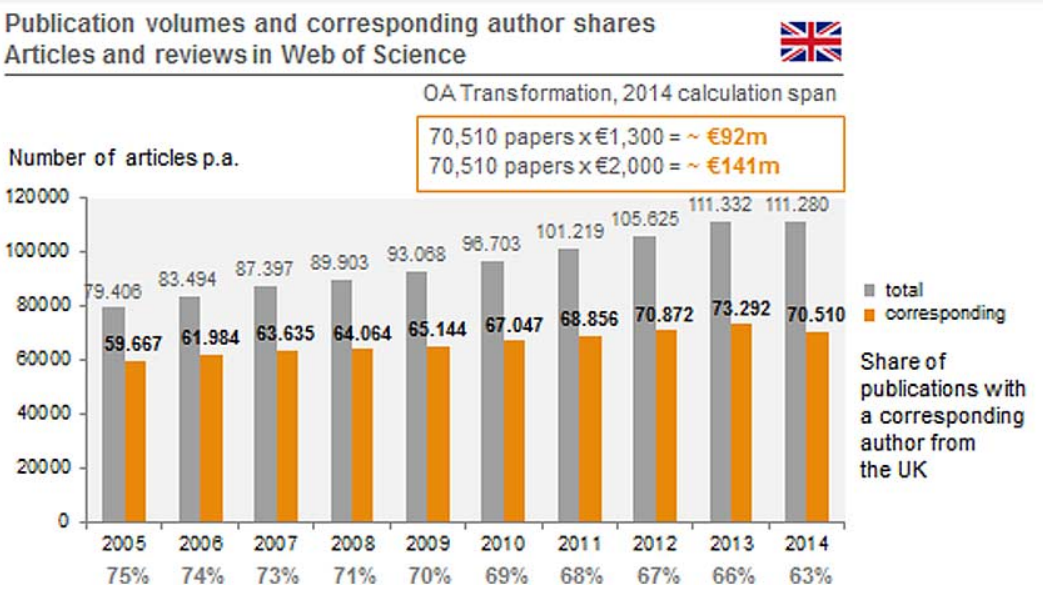

Fig. 3. Cost projections for a full-fledged OA scenario in the UK.

The Berlin 12 Conference held in December 2015 convened 100 delegates from 19 countries, along with some international organizations, and had two principal outputs in support of the proposed transition to OA. ${ }^{3}$ An Expression of Interest acts as a focal document for the collection of institutional signatures in support of the transition; and a Roadmap offering practical steps for interested parties. These two documents were launched in March 2016 as part of the Open Access 2020 (OA2020) campaign. ${ }^{4}$

\footnotetext{
${ }^{3}$ http://www.berlin12.org/.

${ }^{4}$ http://oa2020.org/.
} 
With a shared goal of a swift and smooth transition to OA for the benefit of research, signatories to the Expression of Interest will be expressing support for the transformation of a substantial majority of today's scholarly journals from subscription to OA publishing. Signatories accept that the challenge is to convert those resources that are currently devoted to journal subscriptions into funds that will support sustainable OA business models. The method is to achieve a reorganisation of the underlying cash flows. The initiative will be characterised by a commitment to transparency in the matter of costs and potential savings, and to the adoption of mechanisms that will avoid undue barriers to publication.

The Roadmap borrows best practices from the successes of the pioneering $\mathrm{SCOAP}^{3}$ project $^{5}$ that oversaw the transformation to OA of the journals in particle physics by establishing a network of National Contact Points. At the local institutional level, participants are urged to take practical steps in the form of collecting and analysing their publication and financial data; consolidating subscriptions and OA responsibilities under a single budget and management; and taking their publisher relationships to a new level, for example by engaging in a combined, 'offsetting' model.

\section{Creating stepping stones for the transition to $\mathrm{OA}$}

This new approach, commonly referred to as offsetting, has been established as a transitional model; ${ }^{6}$ it provides a good entry point for a systematic redeployment of licensing costs (subscriptions) to publication costs. The approach attempts to crack the logic of subscriptions by demanding additional open access services based on current sales volumes. In this model the library remains a subscription customer, continues to get the required access rights and secures for its patrons the right to publish in open access. Such transitional approaches have been steadily spreading for about two years and are furthest advanced in Great Britain, the Netherlands, and Austria. In Germany the MPDL has been actively working on transition models, and has been involved in a pilot project with Springer since late 2015. Since other institutions are following this track, the academic information world can expect to see other new contracts being set up very soon. The OA2020 campaign encourages and supports academic libraries to reconfigure themselves for this new world.

The goal for all sides in academic publishing is to bring about an orderly transformation of the business of academic publishing: established practices of journal publishing will continue while 'disruption' will occur only by a strategic rethinking of the financing. Overall, the OA initiative may be expected to inspire the creation of new and better ways of registering, certifying, disseminating, and archiving the fruits of scholarship in the 21 st-century's digital world.

\section{References}

[1] M. Palzenberger, Number of scholarly articles per country. Data on Web of Science listed articles and reviews 2004-2013. doi:10.17617/1.2.

[2] R. Schimmer, K.K. Geschuhn and A. Vogler, Disrupting the subscription journals' business model for the necessary largescale transformation to open access. doi:10.17617/1.3.

\footnotetext{
${ }^{5}$ https://scoap3.org/.

${ }^{6}$ For further reading: The ESAC initiative came up with a 'Joint Understanding of Offsetting' (cf. http://esac-initiative.org/ esac-initiative-releases-a-joint-understanding-ofoffsetting/).
} 